University of Wollongong

Research Online

Faculty of Health and Behavioural Sciences -

Papers (Archive)

Faculty of Science, Medicine and Health

$11-2008$

\title{
Australian consumer attitudes to health claim - food product compatibility for functional foods
}

\author{
P. G. Williams \\ University of Wollongong, peterw@uow.edu.au \\ L. Ridges \\ University of Wollongong, leisa@uow.edu.au \\ M. Batterham \\ University of Wollongong, marijka@uow.edu.au \\ B. Ripper \\ University of Wollongong \\ M. C. Hung \\ University of Wollongong
}

Follow this and additional works at: https://ro.uow.edu.au/hbspapers

Part of the Arts and Humanities Commons, Life Sciences Commons, Other Social and Behavioral Sciences Commons, and the Public Health Commons

\section{Recommended Citation}

Williams, P. G.; Ridges, L.; Batterham, M.; Ripper, B.; and Hung, M. C.: Australian consumer attitudes to health claim - food product compatibility for functional foods 2008.

https://ro.uow.edu.au/hbspapers/99

Research Online is the open access institutional repository for the University of Wollongong. For further information contact the UOW Library: research-pubs@uow.edu.au 


\title{
Australian consumer attitudes to health claim - food product compatibility for functional foods
}

\begin{abstract}
This study with Australian consumers investigated how appealing different health claims combined with particular food carriers were to Australian consumers, and compared the results of a similar study with Dutch consumers. 149 shoppers considered up to 30 different food concepts, rating how 'attractive', 'believable', and 'new and different' they found each concept and their 'intention to try'. Each variable was significantly related to intention to try $(p<0.001)$ and together explained $56 \%$ of the intention score. Claims and carriers independently had a significant effect on ratings of attractiveness and intention to try but, unlike the Dutch study, the carrier was a more important predictor of intention to purchase than the claim. Implications for regulation of health claims for food are discussed.
\end{abstract}

\section{Keywords}

era2015, health claims, functional foods, consumers, food regulation

\section{Disciplines}

Arts and Humanities | Life Sciences | Medicine and Health Sciences | Other Social and Behavioral Sciences | Public Health | Social and Behavioral Sciences

\section{Publication Details}

This article was originally published as Williams, P, Ridges, L, Batterham, M, Ripper, B, Hung and MC, Australian consumer attitudes to health claim - food product compatibility for functional foods, Food Policy, 33(6), 640-643, 2008. Copyright Elsevier 2008. Original journal article available here 
Title:

\title{
Australian consumer attitudes to health claim - food product compatibility for functional foods
}

Authors:

\author{
Peter Williams ${ }^{1}$ BSc(Hons) DipNutrDiet MHP PhD FDAA \\ Leisa Ridges ${ }^{1}$ BSc(Hons) PhD Candidate \\ Marijka Batterham ${ }^{1}$ BSc MSc(Nutr\&Diet) GDipMedStat PhD AdvAPD \\ Bridget Ripper ${ }^{2}$ MSc(Nutr \& Diet) candidate \\ Man Chi Hung ${ }^{2}$ BNutrDiet candidate
}

\author{
Addresses: \\ ${ }^{1}$ Smart Foods Centre, University of Wollongong, Wollongong, NSW 2522 Australia \\ ${ }^{2}$ School of Health Sciences, University of Wollongong, Wollongong, NSW 2522 Australia
}

\section{Contributions:}

P Williams and L Ridges planned the study and prepared the manuscript. B Ripper and M Hung carried out the surveys and analysed results; M Batterham assisted with statistical analysis and manuscript revision.

Correspondence: A/Prof Peter Williams

Tel: $\quad 61242214085$

FAX: $\quad 61242214844$

Email:_ peterw@uow.edu.au

Word count: $\quad 3029$

Version Short Communication-v1 


\begin{abstract}
This study with Australian consumers investigated how appealing different health claims combined with particular food carriers were to Australian consumers, and compared the results of a similar study with Dutch consumers. 149 shoppers considered up to 30 different food concepts, rating how 'attractive', 'believable', and 'new and different' they found each concept and their 'intention to try'. Each variable was significantly related to intention to try $(\mathrm{p}<0.001)$ and together explained $56 \%$ of the intention score. Claims and carriers independently had a significant effect on ratings of attractiveness and intention to try but, unlike the Dutch study, the carrier was a more important predictor of intention to purchase than the claim. Implications for regulation of health claims for food are discussed.
\end{abstract}

Key words: health claims; functional foods; consumers; food regulation 


\section{Introduction}

In Australia and New Zealand, regulations currently restrict the use of claims on food to nutrient content and health maintenance claims. Claims about the prevention or reduction of disease risk are currently prohibited (with one exception about folate) although this may soon change (Food Standards Australia New Zealand, 2007). Nonetheless, health claims are already present in the Australian food market on labels, in advertising and the internet (Williams et al, 2007).

The effect claims have on consumer perceptions has not been extensively studied (Williams, 2005). There have been surveys on consumer attitudes generally (Food Standards Australia New Zealand, 2003) and one experimental study comparing different formats of label claims (Singer et al, 2006), but there has been no research about the combinations of health claims and food carriers in Australia.

In 2002, van Kleef and others conducted a study with Dutch consumers examining the effect that a range of health claims and food carriers had on consumer perceptions and their intention to try a novel functional food (van Kleef et al, 2002; van Kleef et al, 2005). There are differences between countries in consumer attitudes to functional food propositions (Bech-Larsen \& Grunert, 2003). This study was designed to test whether there were differences between Australian and Dutch consumers in the effect of health claims and food carriers on perceptions about foods with functional ingredients. It aimed to identify whether the food carrier or claim has more influence on perceptions and intention to try, and which types of foods and claims are seen as more appropriate for functional foods. 


\section{Methods}

\section{Participants}

Participants were recruited from two shopping malls in an urban area south of Sydney, Australia. Shoppers were invited to participate at a stall in the mall and offered an incentive voucher for coffee and cake. Subjects were interviewed to collect demographic information and asked whether they considered the health aspects of food when shopping. Only volunteers who were above 18 years, were the primary household food purchaser and stated that health was an important consideration when shopping were included. The University of Wollongong Human Research Ethnics Committee approved the study.

\section{Study design}

Ten health claims and food carriers (Table 1), based on those used in the previous Dutch study, were combined to create 100 health claim-carrier concepts. One sole change in this study was that the claim 'reduces the risk of dementia' was changed to 'reduces the risk of age-related deterioration of the eye', because this is a current Australian public health priority (Department of Health and Ageing, 2005).

Concepts were presented to participants as in the previous study (van Kleef et al., 2005), on a black and white A4 size card, with a claim statement and a picture of the food, but without identification of the putative active ingredient. Participants were given up to 3 bundles of 10 concepts on a predetermined pattern so that each concept was reviewed by at least 30 people. Participants rated how 'attractive', 'believable' and 'new and different' they found the concepts, using a 5-point scale with end-points labelled 'not at all' to 'very', and asked 'would you like to try this product?' to determine their intention to try, with a scale from 'absolutely not' to 'absolutely'.

\section{Data analysis}

Analysis of variance (ANOVA) was used to estimate the influence the claim and carrier independently, and the influence of the claim-carrier interaction on the four consumer measures - attractiveness, believability, uniqueness and intention to try (the dependent variables). Differences between the means for 'attractiveness' and 'intention to try' were 
analysed using the Student-Newman-Keuls multiple range test. Regression analysis determined how the three variables 'attractive', 'believable', 'new and different' (and combination of those) contributed to intention to try. Analyses were conducted using the Statistical Package for Social Sciences (V10.0.5: SPSS Inc., Chicago, USA). Statistical differences were regarded as significant at $\mathrm{p}<0.05$. 


\section{Results}

149 subjects participated: $41 \%$ male and $59 \%$ female; $37 \%$ aged $18-34 \mathrm{y}, 40 \%$ aged $35-54 \mathrm{y}$, and $23 \%$ aged $55 y$ or over; $78 \%$ were tertiary educated and $37 \%$ said they had to consider a person suffering from a specific disease when shopping. Diabetes, heart disease and cancer were the conditions most prevalent in these shoppers' households.

ANOVA indicated that both health claims and carriers independently had a significant effect $(\mathrm{p}<0.001)$ on ratings of intention to try, credibility, uniqueness and attractiveness. The carrier was a more important factor than the claims themselves. For credibility, uniqueness, and intention to try, small but statistically significant two-way-interactions were found, indicating that certain combinations of health claims and carriers were evaluated differently from what would be expected from evaluations of the claim and carrier separately.

All 10 health claims independently had a positive influence on concept attractiveness, with scores $>3.0$ (Table 2). For intention to try, claims about serious diseases rated more highly than those promising psychological or appearance benefits. Results by carrier are presented in Table 3. Health claims on tea, yoghurt, soup and brown bread had the highest ratings on intention to try, significantly different to those for ice-cream, chewing gum, margarine and meat replacer.

Regression analysis (Table 4) showed that intention to try was driven independently by concept attractiveness, believability and uniqueness. Each factor alone was statistically significant, with attractiveness being the most influential factor on intention to purchase. Together these three variables accounted for $56 \%$ of the variation in intention to try. 


\section{Discussion}

\section{Limitations of the study}

The subjects were not a random sample of consumers. They were more highly educated than average and expressed interest in the health properties of the foods they purchased. However such consumers are exactly those most likely to be interested in health claims for food when making purchase decisions (Nayga, 1996).

A second limitation relates to the study design. To control for several factors known to influence consumers' perceptions - format and design in terms of graphics, colour, size, and placement of the claim print (Stewart \& Martin, 1994) - participants were shown only concept pictures rather than more realistic product packaging. This could affect product beliefs and purchase intention (Bone \& France, 2001). Lastly, the active ingredients were not described, which may have reduced claim credibility.

The results confirm two of the major findings from the Dutch study (van Kleef et al., 2005). Willingness to try a functional food was driven mostly by the attractiveness of the claimed health benefit. Perceptions of the credibility and uniqueness of the claim also significantly enhanced purchase intent, but to a lesser extent (Table 4). Secondly, the lack of significant interaction between health claim and carrier for attractiveness indicates that consumers considered the claim and the carriers independently of each other.

This study demonstrated that food carriers are influential on consumer perceptions, independent of the health claim. This supports results from a European study which found a link between perceptions of the healthiness of a functional food and intention to try (BechLarsen \& Grunert, 2003). That study noted perceptions of healthiness are often based on prior beliefs of the nutritional quality of the carrier, a finding also reported with American consumers (Levy et al, 1997). Canadians have also expressed a preference for health claims to be carried on commonly perceived healthier foods, such as bread and yoghurt (National Institute of Nutrition, 2000). 
As in the Dutch study, claims about serious diseases were rated more attractive, and increased likely intention to try more than claims for psychological or appearance benefits. This is consistent with the health framing literature (Levin et al, 1998) and results from other studies (Food Standards Agency, 2002).

Attractiveness, credibility and uniqueness of the food concept accounted for only $56 \%$ of the likely intention to try. Another Australian study, on intention to use omega-3 enriched foods, also reported attitude to the food and claim accounted for $56 \%$ of intention to try (Patch et al, 2005). This implies almost half of the intention to try is related to other factors. It is known that gender, dietary pattern and age (Saher et al, 2004), nutrition knowledge (Bogue et al, 2005), taste preferences (Verbeke, 2006), advertising effects (Byrd-Bredbenner \& Grasso, 2001), and education level (Fullmer et al, 1991) all influence decisions to use functional foods.

\section{Differences between Australian and Dutch consumers}

In both countries, ratings of attractiveness and intention to try were higher for foods perceived to be healthier (Sijtesma et al, 2004): tea, yoghurt and brown bread ranked as the top three in Australia, while ice-cream, chewing gum and chocolate were ranked lower. In general, the Australians gave higher absolute ratings of intention to try for all carriers; Dutch consumers rated only one food greater the 3.2, compared to five of the ten foods by the Australians. Another difference was that the health claim was a much less important factor for the Australians than the carrier when rating intention to try (the F value of health claims and carriers for Australians were 7.2 and 14.0 respectively, compared to 26.5 and 6.1 with Dutch consumers).

Both the Dutch and Australians rated yoghurt and brown bread among the top three foods for attractiveness and intention to try, and meat replacer and chewing gum as the lowest two, but margarine was perceived differently. It was ranked $2^{\text {nd }}$ out of 10 foods in the Netherlands, versus $8^{\text {th }}$ in Australia. This may relate to the longer history of health claims on such foods in Europe (Wolfs et al, 2006) compared to Australia, where there is significant scepticism about claims on high fat foods (Chan et al, 2005). The fact that tea was rated the most attractive 
food carrier by Australian consumers may be influenced by the widespread presence of health claims on teas in the Australian market (Williams et al, 2006). 


\section{Conclusions}

These results are consistent with other research suggesting that consumers expect health claims to be on healthier foods and that claims about prevention of serious diseases are more appealing than those about appearance or psychological benefits. These findings support regulatory options that establish nutritional eligibility requirements for foods which carry health claims and also point to the need for particular care in approval of claims for serious diseases. There were some noticeable differences in the reactions of Australian and Dutch consumers, particularly in views about which foods were appropriate to carry health claims. This suggests that regulators need to conduct consumer research with their local populations to inform policy decisions. 
Table 1. Selected health claims and carriers.

\section{Health Claims}

1. Protects against damage to skin from UV irradiation

2. Gives extra energy

3. Helps maintain healthy cholesterol levels

4. Helps keep a youthful appearance

5. Strengthens the natural defence of the body against frequently occurring diseases (like a cold)

6. Reduces the risk of certain types of cancer

7. Reduces the risk of osteoporosis

8. Reduces the risk of heart disease

9. Reduces stress

10. Reduces the risk of age-related deterioration of the eye

\section{Carriers}

A. Brown Bread

B. Bar of Chocolate

C. Chewing Gum

D. Margarine

E. Meat replacer

F. Pills

G. Ice-cream

H. Soup

I. Tea

J. Yoghurt 
Table 2. Subject ratings of attractiveness and intention to try for each health claim

Health claims

Mean (SD)

Reduces the risk of certain types of cancer

Reduces the risk of heart disease

Helps maintain healthy cholesterol levels

Strengthens the natural defence of the body against frequently occurring diseases (like a cold)

Reduces stress

Reduces the risk of osteoporosis

Reduces the risk of age-related deterioration of the eye

Gives extra energy

Protects against damage to skin from UV irradiation

Helps keep a youthful appearance
Attractiveness

Intention to try

$3.88^{\mathrm{d}} \quad(1.25)$

Mean (SD)

$\begin{array}{llll}3.88^{\mathrm{d}} & (1.25) & 3.45^{\mathrm{b}} & (1.37) \\ 3.76^{\mathrm{cd}} & (1.28) & 3.43^{\mathrm{b}} & (1.30) \\ 3.72^{\mathrm{cd}} & (1.30) & 3.48^{\mathrm{b}} & (1.33)\end{array}$

$3.68^{\mathrm{cd}}(1.31)$

$3.42^{\mathrm{b}} \quad(1.35)$

$3.60^{\mathrm{c}} \quad(1.37)$

$3.27^{\mathrm{b}} \quad(1.47)$

$3.60^{\mathrm{c}} \quad(1.31)$

$3.28^{\mathrm{b}}$

$3.55^{\text {bc }}$ (1.34)

$3.20^{\mathrm{ab}}$

$3.35^{\mathrm{ab}}$ (1.33)

$3.20^{\mathrm{ab}}$

$3.33^{\mathrm{ab}}(1.45)$

$2.97^{\mathrm{a}} \quad(1.49)$

$3.29^{\mathrm{a}} \quad(1.48)$

$2.97^{\mathrm{a}}$

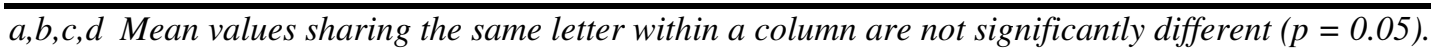


Table 3. Subject ratings of attractiveness and intention to try for each carrier

\begin{tabular}{lcc}
\hline Carriers & $\begin{array}{c}\text { Attractiveness } \\
\text { Mean (SD) }\end{array}$ & $\begin{array}{c}\text { Intention to try } \\
\text { Mean (SD) }\end{array}$ \\
\hline Tea & $3.99^{\mathrm{a}}(1.17)$ & $3.63^{\mathrm{a}}(1.28)$ \\
Yoghurt & $3.95^{\mathrm{a}}(1.14)$ & $3.63^{\mathrm{a}}(1.31)$ \\
Soup & $3.79^{\mathrm{a}, \mathrm{b}}(1.23)$ & $3.43^{\mathrm{a}, \mathrm{b}}(1.34)$ \\
Brown Bread & $3.58^{\mathrm{b}, \mathrm{c}}(1.27)$ & $3.44^{\mathrm{a}, \mathrm{b}}(1.29)$ \\
Ice-cream & $3.57^{\mathrm{b}, \mathrm{c}}(1.42)$ & $3.11^{\mathrm{c}, \mathrm{d}}(1.49)$ \\
Bar of Chocolate & $3.54^{\mathrm{c}}(1.39)$ & $3.28^{\mathrm{b}, \mathrm{c}}(1.42)$ \\
Pills & $3.49^{\mathrm{c}}(1.37)$ & $3.16^{\mathrm{c}, \mathrm{d}}(1.39)$ \\
Margarine & $3.48^{\mathrm{c}}(1.34)$ & $3.16^{\mathrm{c}, \mathrm{d}}(1.40)$ \\
Chewing gum & $3.20^{\mathrm{d}}(1.51)$ & $2.89^{\mathrm{d}}(1.49)$ \\
Meat replacer & $3.17^{\mathrm{d}}(1.43)$ & $2.93^{\mathrm{d}}(1.44)$ \\
\hline
\end{tabular}

$a, b, c, d$ Mean values sharing the same letter within a column are not significantly different ( $p=0.05)$. 
Table 4. Results of regression analysis for intention to try contributed by the variables: 'attractive', 'believable', 'new and different' and the combination of all three variables.

\begin{tabular}{ccccc}
\hline Attractive & Believable & $\begin{array}{c}\text { New and } \\
\text { different }\end{array}$ & $\begin{array}{c}\text { Combination of } \\
\text { all variables }\end{array}$ \\
\hline$\beta$ & 0.61 & 0.23 & 0.059 & 0.56 \\
$\mathrm{P}$ & $<0.001$ & $<0.001$ & $<0.001$ & $<0.001$ \\
\hline
\end{tabular}




\section{References}

Bech-Larsen T, Grunert K (2003). The perceived healthfulness of functional foods. A conjoint study of Danish, Finnish and American consumers' perceptions of functional foods. Appetite, 40: 9-14.

Bogue J, Coleman T, Sorenson D (2005). Determinants of consumers' dietary behaviour for health-enhancing foods. Br Food J, 107: 4-16.

Bone P, France K (2001). Package graphics and consumer product beliefs. J Bus Psychol, 15: 467-489.

Byrd-Bredbenner C, Grasso D (2001). The effects of food advertising policy on televised nutrient content claims and health claims. Family Econom Nutr Rev, 13: 37-49.

Chan C, Patch C, Williams P (2005). Australian consumers are sceptical about but influenced by claims about fat on food labels. Eur J Clin Nutr, 59: 148-151.

Department of Health and Ageing (2005). Eye health in Australia: a background paper to the National Framework for Action to Promote Eye health and prevent avoidable blindness and vision loss. Available at:

http://www.health.gov.au/internet/wcms/publishing.nsf/Content/ageing-eyehealthpublication.htm. Canberra, Commonwealth Department of Health and Ageing.

Food Standards Agency (2002). Health claims on food packaging. Consumer-related qualitative research. London, Food Standards Agency.

Food Standards Australia New Zealand (2003), Food Labelling Issues: Quantitative Research with Consumers. Evaluation Report Series No 4, Canberra, FSANZ.

Food Standards Australia New Zealand (2007). P293 - Nutrition, Health and Related Claims. Preliminary Final Assessment Report. Available at: http://www.foodstandards.gov.au/standardsdevelopment/proposals/proposalp293nutrit ionhealthandrelatedclaims/index.cfm. Canberra, FSANZ.

Fullmer S, Geigher C, Parent C (1991). Consumers' knowledge, understanding and attitudes toward health claims on food labels. J Am Diet Assoc, 91: 166-171. 
Levin I, Schneider S, Gaeth G (1998). All frames are not created equal: A typology and critical analysis of framing effects. Org Behav Hum Dec Proc, 86: 205-18.

Levy A, Derby B, Roe B (1997). Consumer Impacts of Health Claims: An Experimental Study. Washington DC, Division of Market Studies, Centre for Food Safety and Applied Nutrition, Food and Drug Administration.

National Institute of Nutrition (2000), Consumer awareness of and attitudes toward functional foods, Ottawa, National Institute of Nutrition.

Nayga R (1996). Determinants of consumers' use of nutritional information on food packages. J Agric Appl Econ, 28: 303-312.

Patch C, Tapsell L, Williams P (2005). Attitudes and intentions towards purchasing novel foods enriched with omega-3 fatty acids. J Nutr Educ Behav, 37: 235-241.

Saher M, Arvola A, Lindeman M, Lahteenmaki L (2004). Impressions of functional food consumers. Appetite, 42: 79-89.

Sijtesma S, Backus G, Linnemann A, Jongen W (2004). Consumer orientation of product developers and their product perception compared to that of consumers. Trends Food Sci Technol, 15: 489-497.

Singer L, Williams P, Ridges L, Murray S, McMahon A (2006). Consumer reactions to different health claim formats on food labels. Food Aust, 58: 92-97.

Stewart D, Martin I (1994). Intended and unintended consequences of warning messages: a review and synthesis of empirical research. J Pub Pol Marketing, 13: 1-19.

van Kleef E, van Trijp C, Luning P, Jongen W (2002). Consumer-oriented functional food developments: how well do functional disciplines reflect the 'voice of the consumer'? Trends Food Sci Technol, 13: 93-101.

van Kleef E, van Trijp H, Luning P (2005). Functional foods: health claims-food product compatibility and the impact of health claim framing on consumer evaluation. Appetite, 44: 299-308.

Verbeke W (2006). Functional foods: Consumer willingness to compromise on taste for health? Food Qual Pref, 17: 126-131. 
Williams P (2005). Consumer understanding and use of health claims for foods. Nutr Rev, 63: 256-264.

Williams P, Ridges L, Yeatman H, Houston A, Rafferty J, Roesler A et al (2006). Nutrition function, health and related claims on packaged Australian food products - prevalence and compliance with regulations. Asia Pacific J Clin Nutr, 15: 10-20.

Williams P, Tapsell L, Jones S, McConville K (2007). Health claims for food made in Australian magazine advertisements. Nutr Diet, 64: 234-240.

Wolfs M, de Jong N, Ocke M, Verhagen H, Verschurem W (2006). Effectiveness of customary use of phytosterol/-stanol enriched margarines on blood cholesterol lowering. Food Chem Toxicol, 44: 1682-1688. 